\title{
A comparative study of three types of grid connected photovoltaic systems based on actual performance
}

\begin{abstract}
In this study, three photovoltaic (PV) systems are evaluated based on actual performance. The energy generation of three types of PV systems namely concentrating PV system (6 units $\times 1 \mathrm{kWp}), \mathrm{PV}$ system with sun tracking flat $(2$ units $\times 1 \mathrm{kWp})$ and fixed flat PV system (2 units $\times 1 \mathrm{kWp})$ is analyzed in this research. Data analysis for ten consecutive months consisting of 12,190 samples of 15 min interval is done. The performance evaluation is done using energy yield, yield factor, capacity factor, power efficiency and PV array efficiency. Based on the experiment data, it is concluded that tracking flat PV system is the most suitable system for Malaysia in normal operation mode with average daily generation of $4.7 \mathrm{~kW} \mathrm{~h}$ (141 kW h as a monthly average), system efficiency of $11 \%$, power efficiency of $85 \%$, average daily yield factor of $2.3 \mathrm{~kW} \mathrm{~h} / \mathrm{kWp}$ and capacity factor of $32 \%$. This study also highlights the PV energy (EPV) models for each PV generators with respect to the environmental factors. The advantage of employing a tracking flat system as compared to the fixed flat system is considered based on the effectiveness of the dual-axis tracking mechanism tracking the sun for maximum power output.
\end{abstract}

Keyword: PV system; Concentrating PV system; Sun tracking PV system; Linear regression 